\title{
A importância da Universidade Federal na prestação de cuidados à saúde das populações ribeirinhas do interior do Amazonas
}

\author{
The importance of the Federal University in providing health care for riverside populations \\ in the interior of Amazonas
}

\section{La importancia de la Universidad Federal en la atención de la salud de las poblaciones ribereñas del interior de Amazonas}

\begin{abstract}
Yara da Silva dos Reis ${ }^{1 *}$, Raynah Letícia Feitosa Torres ${ }^{1}$, Greyce Kelly Paes de Souza1, Paula Christine Feitosa de Castro', Tanny Thaylle Gomes de Souza1, Jaynne de Souza Dantas ${ }^{1}$, Sibele Naiara Ferreira Germano ${ }^{1}$, José Carlos Ferreira Pinheiro Júnior ${ }^{1}$, Marcelo Henrique da Silva Reis ${ }^{1}$, Jéssica Karoline Alves Portugal ${ }^{1}$.
\end{abstract}

\section{RESUMO}

Objetivo: Descrever a importância da Universidade Federal para o interior do Estado do Amazonas, contribuindo na formação de recursos humanos especializados na área da saúde e dando retorno imediato ao município em que está localizada. Relato de experiência: Trata-se de um relato de experiência do tipo descritivo, obtido ao longo dos últimos 4 anos de gestão profissional envolvendo as ações de saúde municipais ligadas diretamente ao suporte de acadêmicos da área de saúde de uma Universidade Federal, localizada no interior do Amazonas, entre março de 2017 a julho de 2021. No referido período, os gestores municipais acompanharam e participaram ativamente das atividades intersetoriais implementadas, além de estarem próximos e constatarem a grande importância que a Universidade exerce. Considerações finais: $O$ advento da Universidade no interior permitiu a inserção dos acadêmicos no contexto da vida ribeirinha, possibilitando a compreensão da cultura, modo de vida, cuidado com a saúde, vida social, acessibilidade a saúde, educação e informação. Os futuros profissionais também puderam contribuir na assistência de saúde, colocando na prática o conhecimento adquirido na graduação, contribuindo de forma ef etiva na saúde do caboclo ribeirinho.

Palavras-chave: Atenção primária à saúde, Universidades, População rural.

\begin{abstract}
Objective: To describe the importance of the Federal University for the interior of the State of Amazonas, contributing to the training of human resources specialized in health and providing immediate feedback to the municipality in which it is located. Experience report: This is a descriptive experience report, obtained over the last 4 years of professional management involving municipal health actions directly linked to the support of academics in the health area of a Federal University, located in the countryside do Amazonas, between March 2017 and July 2021. During that period, municipal managers actively followed and participated in the implemented intersectorial activities, in addition to being close and realizing the great importance that the University exerts. Final considerations: The advent of the University in the interior allowed the insertion of academics in the context of riverside life, enabling an understanding of the culture, way of life, health care, social life, accessibility to health, education and information. Future professionals were also able to contribute to health care, putting into practice the knowledge acquired during graduation, effectively contributing to the health of the riverside caboclo.
\end{abstract}

Key words: Primary health care, Universities, Rural population.

1 Universidade Federal do Amazonas (UFAM), Coari - AM. “E-mail: jessika.portugal@gmail.com

SUBMETIDO EM: 12/2021

ACEITO EM: 12/2021

PUBLICADO EM: 12/2021 


\section{RESUMEN}

Objetivo: Describir la importancia de la Universidad Federal para el interior del Estado de Amazonas, contribuyendo a la formación de recursos humanos especializados en salud y brindando retroalimentación inmediata al municipio en el que se ubica. Informe de experiencia: Se trata de un informe descriptivo de experiencia, obtenido durante los últimos 4 años de gestión profesional que involucran acciones de salud municipal directamente vinculadas al apoyo de académicos en el área de salud de una Universidad Federal, ubicada en el campo do Amazonas, entre marzo 2017 y julio 2021. Durante ese período, los gestores municipales siguieron y participaron activamente en las actividades intersectoriales implementadas, además de estar cerca y darse cuenta de la gran importancia que ejerce la Universidad. Consideraciones finales: El advenimiento de la Universidad al interior permitió la inserción de los académicos en el contexto de la vida ribereña, posibilitando la comprensión de la cultura, forma de vida, salud, vida social, ac cesibilidad a la salud, educación e información. Los futuros profesionales también pudieron contribuir a la atención de la salud, poniendo en práctica los conocimientos adquiridos durante la graduación, contribuyendo ef ectivamente a la salud del caboclo ribereño.

Palabras clave: Atención primaria de salud, Universidades, Población rural.

\section{INTRODUÇÃO}

O Sistema Único de Saúde (SUS), é um dos únicos no mundo que não cobra pelos serviços prestados, isso é fruto de anos da luta popular, desde a reforma sanitária. Esse sistema tem como base os princípios da equidade, integralidade, universalidade, além das ações de promoção, prevenção e tratamento de agravos, contribuindo significativamente na diminuição das desigualdades sociais, cuidando de cada indivíd uo conforme sua necessidade. Neste sentido, o SUS coloca a saúde como um direito a ser assegurado pelo Estado, garantindo acesso às ações e serviços de saúde de acordo com a singularidade do usuário, independentemente da cor, raça, sexo, classe social, orientação sexual, posição política e demais características individuais. O SUS também está presente na formação acadêmica na área da saúde, seja da rede pública ou privada (BRASIL, 1990).

O meio universitário é um espaço que representa grande relevância para o desenvolvimento humano, visto que permite a expansão das habilidades intelectuais do indivíduo, além de moldá-lo para a vida profissional, de forma que possa contribuir ef etivamente na vida do próximo. A época de formação também marca grandes obstáculos, como por exemplo: impacto na saúde mental, dificuldade financeira, transições e mudanças bruscas na vida do acadêmico, dentre outros empecilhos (CERCHIARI EAN, et al., 2005; PADOVANI RC, et al., 2014).

Em âmbito nacional, nos últimos 20 anos houve a descentralização das Universidades para os interiores, sejam federais, estaduais ou privadas. Com essa chegada, o aluno do interior não necessitava mais ter que morar nas grandes metrópoles para cursar nível superior, representando um grande ganho social, pois possibilitou que muitos estudantes pobres e de baixa renda tivessem oportunidade de se qualificar e ter uma profissão (ZARANTONELI RCG e ARADELA VCA, 2020).

O Amazonas também viveu essa transformação, diversas universidades se expandiram para o interior do Estado, oferecendo vários cursos de graduação, dentre eles, destacamos: licenciaturas, nutrição, enfermagem, educação física, medicina, fisioterapia, farmácia, biotecnologia, direito, engenharia de software e outros. Em relação a área de saúde, esse grande marco foi primordial para que filhos da terra pudessem estudar em seus seios familiares e atuar diretamente na comunidade em que cresceram e possuem vínculo. A vinda da universidade foi importante na vida dos residentes das zonas rurais dos municípios do interior, pois através de suas atividades e projetos pôde prestar assistência à saúde desses comunitários (REIS MHS, et al., 2019).

Grande parte dos povos que residem nesta região necessitam extrair recursos dos rios e florestas para a sobrevivência e são conhecidos como ribeirinhos. Estes indivíduos enfrentam muitas dificuldades em seu cotidiano, grande parcela possui baixa escolaridade, baixa renda, moram em comunidades com precariedade sanitária, compostas porvárias famílias ou em localidades mais isoladas com um núcleo reduzido. Eles são 
mestiços, representando uma mistura de origens: europeia, africana e principalmente indígena, que têm os rios como uma das maiores riquezas, onde é possível utilizá-lo como fonte de alimento, via de transporte, artesanato, moradia e farmacopeia (FRANCO EC, et al., 2015; FRAXE TJP, et al., 2007; GUIMARÃES AF, et al., 2020).

Diante do exposto, o objetivo deste estudo foi descrever a importância da Universidade Federal para o interior do Estado do Amazonas, contribuindo na formação de recursos humanos especializados na área da saúde e dando retorno imediato ao município em que está localizada.

\section{RELATO DE EXPERIÊNCIA}

Trata-se de um relato de experiência do tipo descritivo, obtido ao longo dos últimos 4 anos de gestão profissional envolvendo as ações de saúde municipais ligadas diretamente ao suporte de acadêmicos da área de saúde de uma Universidade Federal, localizada no interior do Amazonas, entre março de 2017 a julho de 2021. No referido período, os gestores municipais acompanharam e participaram ativamente das atividades intersetoriais implementadas, além de estarem próximos e constatarem a grande importância que a Universidade exerce no âmbito local desde o ano de 2006, principalmente em ações desenvolvidas nas áreas de comunidades ribeirinhas.

O município em que as ações ocorreram está situado na região do médio Solimões, distante a quase 400 $\mathrm{km}$ da capital Manaus, com acesso por via fluvial e aérea. É um dos mais ricos do interior, com atividades voltadas à agricultura, pesca e extrativismo de gás natural e petróleo da bacia de Urucu. A população total correspondeu a aproximadamente 83.078 habitantes no ano de 2016, onde cerca de um terço residia nas mais de 200 comunidades ribeirinhas da zona rural, que estão distribuídas em 7 calhas de rios, lagos e igarapés, numa extensão geográfica de $57.976,069 \mathrm{~km}^{2}$. A população urbana cresceu $20,0 \%$ entre 2000 a 2010, no entanto, a rural teve diminuição de 4,6\% (INSTITUTO BRASILEIRO DE GEOGRAFIA E ESTATíSTICA (IBGE), 2010; IBGE, 2021; GAMA ASM, 2018).

Entre as populações ribeirinhas, o acesso à informação e educação são insuficientes, devido à baixa condição educacional e econômica (GAMA ASM, et al., 2018). Sendo assim, é necessária atenção especial a estes comunitários, sobretudo com ações de prevenção de doenças e promoção de hábitos saudáveis. Desta maneira, a prática de educação em saúde pode facilitar a compreensão das temáticas repassadas durante as ações realizadas.

Ao longo dos últimos 4 anos, sempre antes de realizar uma grande ação, a gestão de saúde local sempre pautou os planejamentos a serem executados, e a partir das discussões, os principais temas prioritários explorados para atingir o público-alvo foram: 1) tratamento correto da água com o uso de hipoclorito de sódio; 2) prevenção de infecções sexualmente transmissíveis e uso de preservativos; 3) primeiros socorros durante a ocorrência de acidentes ofídicos; 4) prevenção do câncer do colo do útero; 5) higiene bucal; 6) atribuições do agente comunitário de saúde; 7) prevenção do câncer de pele; 8) consumo racional de medicamentos e os riscos da automedicação.

Em relação a integração Saúde-Educação, dentre os programas pactuados pelo município, destaca-se a atuação do Programa Saúde na Escola (PSE), que em parceria com a Universidade Federal realiza anualmente $\mathrm{o}$ atendimento direto de aproximadamente 2.000 crianças e adolescentes ribeirinhos, entre 06 a 17 anos. Através do PSE é possível levar informação e educação aos estudantes da zona rural, indo além dos temas prioritários explorados de forma geral, pois contempla: palestras de combate ao Aedes aegypti, malária, promoção das práticas corporais de atividade física, palestras educativas e atividades relacionadas à saúde bucal, aplicação tópica de flúor, com distribuição de escovas e creme dental, com escovação supervisionada e levantamento do índice de dentes cariados, perdidos e obturados (CPO-D).

Além disto, os profissionais e acadêmicos envolvidos no PSE são responsáveis pela verificação da situação vacinal (vacina contra a influenza A, Papilomavírus Humano (HPV) e mais recentemente a vacina contra o novo coronavírus), promoção da segurança alimentar e nutricional, alimentação saudável, prevenção da obesidade infantil, direito sexual, reprodutivo, prevenção de Doenças Sexualmente Transmissíveis (DST) e Vírus da Imunodeficiência Humana (AIDS). 
Nas áreas rurais ainda não há unidades de saúde, alguns projetos estão em fase embrionária, mas com grande potencial de alcance nos próximos anos, pois trata-se de um investimento financeiro amplo. Porém, $75 \%$ dessas áreas tem a cobertura de um Agente Comunitário de Saúde (ACS), que atua na Estratégia Saúde da Família (ESF), coordenados diretamente por um enfermeiro numa equipe de até 12 ACS por área, num total de 10 áreas de rios e lagos, com suporte total de 116 ACS, que prestam assistência direta e indireta para aproximadamente 20 mil ribeirinhos (REIS MHS, et al., 2021a).

Diferente da zona urbana, por estarem distantes da sede do município, os agentes são treinados para estarem aptos a enfrentar as problemáticas comuns das áreas rurais, como por exemplo: treinamento de suporte básico de vida (identificação de casos de acidente vascular encefálico, infarto agudo do miocárdio, queimaduras e seus respectivos graus, ferimento por arma branca e arma de fogo, afogamentos, acidente ofídico), preparo de lâminas para diagnóstico de malária, além disto, estão autorizados a remover para zona urbana o paciente que possa apresentar algum risco de vida, recebendo as despesas de combustível utilizada no transporte mediante a comprovação dos documentos (formulário de remoção e cópia do prontuário de atendimento do Hospital local) exigidos pela Secretaria Municipal de Saúde.

A universidade possui grande representatividade na qualificação dos ACS, ao longo dos anos diversos projetos de extensão, iniciação científica e pesquisa foram voltados para esse público. Essa é uma das contrapartidas que a formação acadêmica pode trazer para o município, visto que é essencial capacitar os profissionais que atuam diretamente na assistência à saúde, pois sempre novos protocolos são inseridos ou atualizados, conforme pesquisas vão sendo realizadas.

É válido ressaltar que a Universidade não atua apenas com projetos voltados para a educação em saúde. Em estágios de disciplinas que estudam as populações amazônicas, os acadêmicos ingressam nas viagens de atendimento da Unidade Básica de Saúde Fluvial, Barco da Saúde e ações de imunização com suporte de lancha rápida. Em todas essas atividades eles estão sob supervisão de preceptor da Universidade e da gestão municipal, a fim de garantir maior segurança no desempenho de suas atividades sem que ocorram eventuais prejuízos aos usuários dos serviços de saúde.

\section{DISCUSSÃO}

É desafiador levar o Sistema Único de Saúde (SUS) as regiões mais longínquas do território nacional. A floresta já oferece perigos com os agravos típicos da região, além da exposição a animais selvagens, presentes na mata e nos rios. Entretanto, ao longo da última década, os ribeirinhos que estão em municípios que fazem fronteira com Colômbiae Peru enfrentam todas as adversidades impostas pela natureza e também estão reféns do crime organizado, sobretudo pelo tráfico de entorpecentes, que tem crescido exponencialmente mesmo com todas as medidas de segurança implementadas pelas forças armadas, polícia militar e demais órgãos de segurança pública (REIS MHS, et al., 2020).

Todas as temáticas utilizadas para atingir o público foram pautadas em patologias e intercorrências rotineiras entre os povos ribeirinhos, coletadas a partir de dados de prontuário, entrevista com ACS, coleta de dados de projetos de pesquisas, dados da Unidade Básica de Saúde Fluvial, etc. Essa estratégia tem como foco a redução dessas doenças, colocando a educação em saúde como ferramenta de trabalho.

Neste contexto, constatou-se que é comum a incidência de parasitoses em comunidades rurais, um agravo que atinge todas as faixas etárias, mas possui grande relevância em crianças. A falta de saneamento básico e o consumo da água não tratada podem ter relação com esse problema de saúde. Nas comunidades é comum a utilização de fossas rudimentares, que são buracos onde os dejetos são despejados, mas em épocas da cheia dos rios esse descarte fica inviável e o esgoto é jogado diretamente na água onde os ribeirinhos utilizam para consumir, lavar e preparar alimentos, sendo este o período de surgimento da maioria dos casos (SANTOS FS, et al., 2010).

Na região norte, o número de casos de câncer do colo uterino é bem elevado, em geral, as mulheres dessa região iniciam precocemente a vida sexual, que é um fator de risco para o surgimento da doença (SANTOS MO, 2018). Nas áreas ribeirinhas não é diferente, ocorrem casos com frequência mesmo com todas as 
medidas de prevenção disponíveis na rede pública. Mas porse tratar de áreas mais isoladas geograficamente, é preciso avaliar estratégias que aumentem a cobertura populacional, detectando precocemente o câncer e as lesões precursoras. Neste sentido, destacamos uma pesquisa de grande relevância realizada no âmb ito local com a participação de diversos docentes e egressos da Universidade, que criou um dispositivo de autocoleta do Papanicolau, a fim de identificar a presença de lesões e o Papilomavírus humano (HPV), um estudo inicial para verificar a eficácia do dispositivo, que facilita a coleta do preventivo, pois este exame ainda representa um grande tabu entre mulheres ribeirinhas (TORRES KL, et al., 2018).

Recentemente, com o surgimento da pandemia de Covid-19, a Universidade teve suas atividades paralisadas por vários meses, a fim de garantir a segurança dos acadêmicos em relação ao contágio do novo coronavírus. Mesmo sem a previsão de uma vacina, muitos alunos fizeram valer uma portaria do Ministério da Educação, que dá permissão aos finalistas dos cursos da área de saúde participarem dos atendimentos e ações dos órgãos públicos de saúde durante o enfrentamento da pandemia (MINISTÉRIO DA EDUCAÇÃO, 2020). Uma atitude corajosa, visto que o vírus é um inimigo invisível e desconhecido, neste sentido, com o grande desfalque de profissionais por conta da contaminação, dezenas de acadêmicos estiveram na linha de frente das equipes de saúde, desde os atendimentos em unidades de referência, testagem em massa na zona urbana e rural, e já em 2021, nas ações de imunização nas áreas ribeirinhas (JÚNIOR JCFP, et al., 2020; PORTUGAL JKA, et al., 2021; REIS MHS, et al., 2021b).

Todas essas atividades dão orgulho a classe da saúde, pois são futuros profissionais que colocaram suas vidas sob risco para garantir que vidas fossem salvas. Assim como as diversas pesquisas realizadas ao longo dos anos, que contribuíram diretamente na elaboração de políticas públicas, além do reconhecimento da população ribeirinha no cenário mundial. São fatos que mostram a grande importância da Universidade no interior, proporcionando que os estudantes de baixa renda possam ter formação universitária, contribuindo diretamente na comunidade que reside, mostrando aos governantes a relevância que traz para o local de instalação e sucessivamente a necessidade de grandes investimentos envolvendo a infraestrutura, bolsas de estudo, laboratórios modernos, condições de trabalho aos docentes e incentivo à pesquisa (JÚNIOR JCFP, et al., 2020; REIS MHS, et al., 2021b).

Com a criação da Política Nacional de Atenção Básica (PNAB) e a necessidade de estruturar e capacitar Equipes de Saúde da Família Ribeirinhas, houve demanda para a inclusão de profissionais de saúde que pudessem adentrar ao mercado de trabalho com experiência prévia sobre as peculiaridades das populações ribeirinhas do Amazonas. Neste sentido, o advento da Universidade no interior permitiu a inserção dos acadêmicos no contexto da vida ribeirinha, possibilitando a compreensão da cultura, modo de vida, cuidado com a saúde, vida social, acessibilidade a saúde, educação e informação. Os futuros profissionais também puderam contribuir na assistência de saúde, colocando na prática o conhecimento adquirido na graduação, contribuindo de forma ef etiva na saúde do caboclo ribeirinho.

\section{REFERÊNCIAS}

1. BRASIL. Lei no 8.080, de 19 de setembro de 1990. Lei Orgânica da Saúde. Dispõe sobre as condições para a promoção, proteção e recuperação da saúde, a organização e o funcionamento dos serviços correspondentes e dá outras providências. 1990. Disponível em: http://www.planalto.gov.br/ccivil_03/leis/l8080. Acessado em: 25 de novembro de 2021.

2. CERCHIARI EAN, et al. Utilização do serviço de saúde mental em uma universidade pública. Psicologia Ciência e Profissão, 2005;25(2): 252-265.

3. FRANCO EC, et al. Promoção da saúde da população ribeirinha da região amazônica: relato de experiência. Rev CEFAC, 2015; 17(5): 1521-1530.

4. FRAXE TJP, et al. Comunidades ribeirinhas amazônicas: modos de vida e uso dos recursos naturais. Manaus: EDUA; 2007.

5. GAMA ASM. Automedicação em comunidades ribeirinhas na região do Médio Solimões, Amazonas. Tese (Doutorado em Enfermagem na Saúde do Adulto). Universidade de São Paulo (USP), São Paulo, 2016; 115 p.

6. GAMA ASM, et al. Inquérito de saúde em comunidades ribeirinhas do Amazonas, Brasil. Caderno de Saúde Pública, 2018;34(2).

7. GUIMARÄES AF, et al., Acesso a serviços de saúde por ribeirinhos de um município no interior do estado do Amazonas, Brasil. Rev Pan Amaz Saude, 2020;11. 
8. INSTITUTO BRASILEIRO DE GEOGRAFIA E ESTATÍSTICA (IBGE). Cidades: informações completas. Disponível em: http://cidades.ibge.gov.br/xtras. Acessado em:25 de novembro de 2021.

9. INSTITUTO BRASILEIRO DE GEOGRAFIA E ESTATÍSTICA (IBGE). Sinopse do censo demográfico de 2010. Disponível em:http://cidades.ibge.gov.br/xtras. Acessado em:25 de novembro de 2021.

10. JÚNIOR JCFP, et al. Atuação de acadêmicos de enfermagem nas ações de enfrentam ento da covid-19 em comunidades ribeirinhas do Amazonas: relato de experiência. Revista Eletrônica Acervo Saúde, 2020;12(10): e5049.

11. MINISTÉRIO DA EDUCAÇÃO. 2020. Portaria n. 356, de 11 de março de 2020. Disponível em: https://www.in.gov.br/en/web/dou. Acessado em 25 de novembro de 2021.

12. PADOVANI RC, et al. Vulnerabilidade e bem-estar psicológicos do estudante universitário. Revista Brasileira de Terapias, 2014;10(1):2-10.

13. PORTUGAL JKA, et al. Acadêmicos de enfermagem do interior do Amazonas em missões ribeirinhas durante a pandemia de covid-19. Revista Eletrônica Acervo Saúde, 2021;13(11): e9320.

14. REIS MHS, et al. Ações de saúde em populações ribeirinhas no interior do estado do Amazonas: Relato de experiência. In SchweickardtJC. Atenção Básica na região amazônica: Saberes e práticas para o fortalecimento do SUS. Porto Alegre: Rede Unida. 2019;171-181.

15. REIS MHS, et al. Características da população ribeirinha de um município do interior do Amazonas. Revista Eletrônica Acervo Saúde, 2021a;13(11): e9273.

16. REIS MHS, et al. O impacto do advento de uma Unidade Básica de Saúde Fluvial na assistência aos povos ribeirinhos do Amazonas. Revista Eletrônica Acervo Saúde, 2020; Sup. 53: e3631.

17. REIS MHS, et al. Vivência de acadêmicos de enfermagem frente à campanha de vacinação da covid-19 em populações ribeirinhas de um município do Amazonas. Revista Eletrônica Acervo Saúde, 2021b;13(12): e9377.

18. SANTOS FS, et al. Prevalência de enteroparasitismo em crianças de com unidades ribeirinhas do Município de Coani, no médio Solimões, Amazonas, Brasil. Rev Pan Amaz Saude, 2010;1(4): 23-28

19. SANTOS MO. Estimativa 2018: Incidência de Câncer no Brasil. Revista Brasileira de Cancerologia, 2018;64(1):119120.

20. SOUSA IS. As condições de vida e saneamento nas comunidades da área de in fluência do gasoduto Coari-Manaus em Manacapuru - AM. Hygeia, 2009;5(9): 88-98.

21. TORRES KL, et al. Self-sampling coupled to the detection of HPV 16 and 18 E6 protein: A promising option for detection of cervical malignancies in remote areas. PLoS One, 2018; 0201262.

22. ZARANTONELI RCG, PARADELA VCA. Descentralização de poder nas universidades públicas brasileiras: uma comparação entre universidade multicampi e estados federativos democráticos. Revista de Gestão do Unilasalle, 2020; 79-98. 